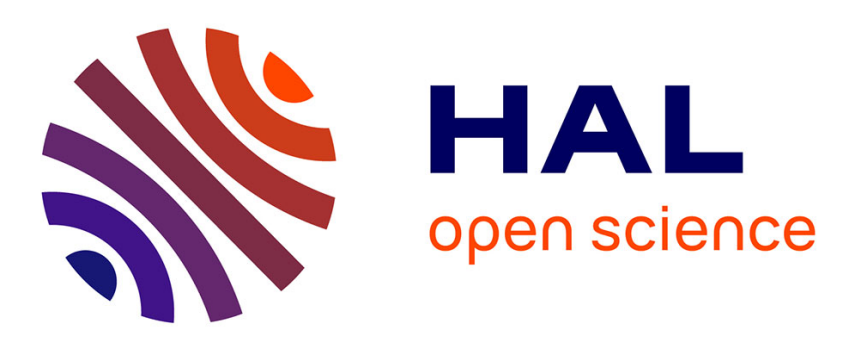

\title{
A Fuzzy Sliding Mode Controller for Reducing Torques Applied to a Rehabilitation Robot
}

Boutheina Maalej, Ahmed Chemori, Hanene Medhaffar, Nabil Derbel

\section{To cite this version:}

Boutheina Maalej, Ahmed Chemori, Hanene Medhaffar, Nabil Derbel. A Fuzzy Sliding Mode Controller for Reducing Torques Applied to a Rehabilitation Robot. SSD 2020 - 17th International Multi-Conference on Systems, Signals \& Devices, Jul 2020, Sfax, Tunisia. pp.740-746, 10.1109/SSD49366.2020.9364130 . lirmm-03135772

\section{HAL Id: lirmm-03135772 https://hal-lirmm.ccsd.cnrs.fr/lirmm-03135772}

Submitted on 9 Feb 2021

HAL is a multi-disciplinary open access archive for the deposit and dissemination of scientific research documents, whether they are published or not. The documents may come from teaching and research institutions in France or abroad, or from public or private research centers.
L'archive ouverte pluridisciplinaire HAL, est destinée au dépôt et à la diffusion de documents scientifiques de niveau recherche, publiés ou non, émanant des établissements d'enseignement et de recherche français ou étrangers, des laboratoires publics ou privés. 


\title{
A Fuzzy Sliding Mode Controller for Reducing Torques Applied to a Rehabilitation Robot
}

\author{
Boutheina Maalej ${ }^{(1,3,4)}$, Hanene Medhaffar ${ }^{(1)}$, Ahmed Chemori ${ }^{(2)}$ and Nabil Derbel ${ }^{(1,4)}$ \\ (1): University of Sfax, ENIS, Laboratory of Control \& Energy Management, Sfax, Tunisia \\ (2): LIRMM, University of Montpellier, CNRS, 161 rue Ada, 34392 Montpellier, France \\ ${ }^{(3)}$ : Clinical Investigation Center, Sfax. (4): Digital Research Center of Sfax. \\ Emails: maalej.boutheina@gmail.com, medhaffar_hanene@yahoo.fr \\ ahmed.chemori@lirmm.fr, n.derbel@enis.rnu.tn
}

\begin{abstract}
Exoskeletons are the most efficient devices used to help children, suffering from several diseases, to walk compared to the use of wheelchairs. In rehabilitation, relearning to walk is very important. In fact, repetitive tasks improve human locomotory performances. This paper aims to deal with the control problem of a two degrees of freedom lower limb exoskeleton. During the control process, high torques are considered as a major constraint. Thus, a fuzzy sliding mode controller is implemented. Moreover, stability analysis are presented using Lyapunov theory.
\end{abstract}

Keywords - Fuzzy Sliding Mode, Lyapunov theory, Exoskeletons, Rehabilitation.

\section{INTRODUCTION}

Stroke, spinal cord injury, traumatic brain injury or cerebral palsy are neurological disorders that can affect limbs [1]. In this purpose, several rehabilitation techniques exist all over the world. Nowadays, exoskeletons are considered as the most efficient technique used to improve the movement ability for elderly persons and handicaps [2]. In fact, they can allow patients to move and to do challenging tasks. Besides, they provide longer training duration with huge number of repetitions comparing to therapists who can get tired while supporting patients with severe motor deficits [3]. Studies have shown that repeating a specific task improves the patient functional walking ability by stimulating the brain plasticity [4]. Furthermore, it helps to reduce patients' anxiety and improve self confidence. Among the new technologies that provide training procedures is Lokomat [5]. It guarantees repetitive training sessions through a predefined gait cycle in a safe environment. In fact, individuals did not feel the fear of falling, rather than, they feel motivated and able to concentrate in order to achieve the gait training goals. In this work, we are interested in the rehabilitation of kids suffering from cerebral palsy. This disease represents the common physical disability of childhood. It causes a reduction of the movement capacity, walking asymmetries and influences kids' motor skills. Moreover, it causes pain, fatigue and musculoskeletal dysfunctions which provide, generally, slow gait speed with disturbed motor control. Statistics prove that 10000 babies are affected by this disease each year worldwide [6]. So, it is needed to find a solution for this population. There is not a specific cure but several treatments are used such as standard and robotic rehabilitation [7]. Among the standard rehabilitation, we can cite, doman and delcato, rood, bobath, vojtaeuropean method, and conductive education therapies [8]. Comparing to the standard rehabilitation, lower limb exoskeletons seem to be more efficient. In fact, they can encourage kids to make longer therapeutic sessions and help physiotherapists to reduce their hard work. Recently, studies focus on the most important part which is the control of the exoskeletons using the adequate controllers [9]. Hence, in the present paper, we propose to control a two degrees of freedom lower limb exoskeleton at the hip and knee joints with a good tracking [6], [7], [10], [11]. The choice of the suitable and the robust controller law is fundamental [12], [13], [14]. In this paper, we propose a robust sliding mode controller [10].

The design of sliding surfaces is one of the factors for improving performances. To achieve robustness, various methods have been suggested [15], [16]. For example, Slotine and Sastry [17] have proposed a time varying sliding surface to remove the reaching phase by imposing a constraint that initial errors be zero in tracking control. Choi et al. [18] have introduced a piecewise continuous moving sliding mode, yet this still includes a reaching phase. Ha et al. [19] have proposed a continuously moving sliding mode obtained by fuzzy tuning. The sliding surface can rotate or shift in the phase space in order to enhance the tracking behavior. The fuzzy tuning considered only the error in the phase plane as the input of the fuzzy system. Medhaffar et al. [20] have replaced fixed sliding surfaces by continuously moving sliding mode surfaces. Moreover, the proposed fuzzy tuning considers the error and the error velocity in the phase plane, as inputs of the fuzzy system, in order to improve control performances.

From the simulation results, we notice that torques are too high, so the idea is to implement a fuzzy sliding mode controller [21]. Then, each position error 
is quantified into five fuzzy subsystems, in order to control the parameters of the sliding mode controller. These parameters take high values for small values of the error, and they take small values for high values of the error. The rest of the paper is organized as follows. The second section introduces the dynamic model of the lower limb exoskeleton. The third section describes the proposed control solutions. The fourth section presents the simulation results. Finally, the fifth and last section presents the conclusion.

\section{DYNAMIC MODEL OF SYSTEM}

Exoskeletons are considered as complex systems. Hence, a dynamic model is established using Lagrange formulation. The proposed model includes the exoskeleton and the kid legs. [22]

$$
M(q) \ddot{q}+C(q, \dot{q}) \dot{q}+G(q)=\tau
$$

with:

$$
\begin{aligned}
\begin{array}{l}
M_{11} \\
M_{12}
\end{array} & =a_{1}+a_{2} \cos q_{2} \\
M_{22} & =a_{21}=a_{3}+a_{4} \cos q_{2} \\
& C_{11}=a_{6} \sin q_{2} \\
& C_{12}=a_{6} \sin q_{2} \\
& C_{21}=\frac{1}{2} a_{6} \sin q_{2} \\
& C_{22}=0 \\
G_{1}= & a_{7} \sin q_{1}-a_{8} \sin \left(q_{1}+q_{2}\right) \\
G_{2}= & a_{9} \sin \left(q_{1}+q_{2}\right)
\end{aligned}
$$

where:

$q, \dot{q}, \ddot{q} \in \mathbb{R}^{2}$ represent the position, velocity and acceleration vectors, respectively,

$M(q) \in \mathbb{R}^{2}$ is the inertia matrix

$C(q, \dot{q}) \dot{q} \in \mathbb{R}^{2}$ represents the Coriolis and centrifugal torques,

$G(q) \in \mathbb{R}^{2}$ denotes the gravity vector,

$\tau \in \mathbb{R}^{2}$ denotes the vector of applied torques by actuators,

$a_{i}$ are positive model parameters which depend on thigh and shank masses, lengths, position of the center of mass, moments of inertia and the gravity acceleration.

\section{FuzZy SLiding Mode CONTROL}

In this section, first, a sliding mode controller is proposed [10]. Define the sliding function as follows:

$$
s=\dot{e}+\lambda e
$$

where: $e=q-q_{d}$ is the tracking error, $\dot{e}=\dot{q}-\dot{q}_{d}$ is the velocity tracking error.

It is required to drive the system to the sliding surface. Hence, we choose $\tau$ such that $\dot{s}=-K \operatorname{sign}(s)$

$$
\dot{s}=M^{-1}(\tau-C \dot{q}-G)-\ddot{q}_{d}+\lambda \dot{e}=-K \operatorname{sign}(s)
$$

We obtain:

$$
\tau=C \dot{q}+G+M\left(\ddot{q}_{d}-\lambda \dot{e}-K \operatorname{sign}(s)\right)
$$

However, due to the large values of the error, especially at the beginning, torques become high. Hence, we suggest to implement a fuzzy sliding mode, which consists to apply small values of parameters $K$ and $\lambda$ for high values of the error, and high values of parameters $K$ and $\lambda$ for small values of the error. Then, each position error $e_{i}(i=1,2)$ is quantified into five fuzzy subsystems as illustrated in Fig. 1 [23].

- $N B$ : Negative Big

- $N S$ : Negative Small

- EZ: Equal Zero

- $P S$ : Positive Small

- PB: Positive Big

Two fuzzy systems are designed as supervisors of the sliding mode controllers. Their outputs are the parameters: $\lambda$ and $K$. In this study, we have chosen triangular membership functions as shown in Fig. 1, regarding their simple expressions, their sum is equal to the unity, and their derivatives are also simple.

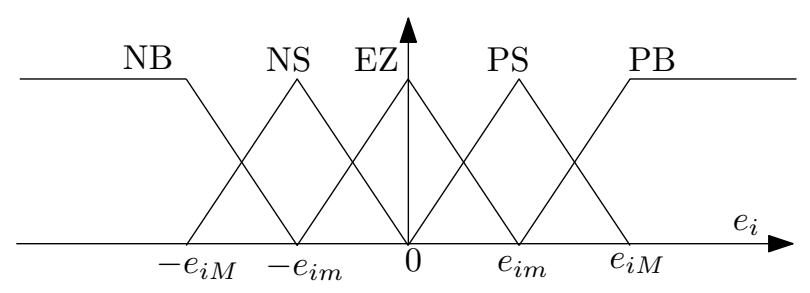

Fig. 1. Membership functions of the fuzzy supervisor

The fuzzy rules are presented in table I. In this case, the choice of the fuzzy systems yields to write:

$$
\sum_{j} \mu_{i j}=1
$$

TABLE I

FUZZY RULES OF FUZZY SYSTEM $i(i=1,2) .\left\{\mu_{i j}\right\}_{j}$ REPRESENT THE MEMBERSHIP FUNCTIONS.

\begin{tabular}{||c||c|c|c|c|c||}
\hline$e_{i}$ & NB & NS & EZ & PS & PB \\
\hline \hline$\mu_{i j}$ & $\mu_{i 1}$ & $\mu_{i 2}$ & $\mu_{i 3}$ & $\mu_{i 4}$ & $\mu_{i 5}$ \\
\hline \hline$\lambda_{i j}$ & $\lambda_{i 1}$ & $\lambda_{i 2}$ & $\lambda_{i 3}$ & $\lambda_{i 4}$ & $\lambda_{i 5}$ \\
\hline$K_{i}$ & $K_{S}$ & $K_{M}$ & $K_{B}$ & $K_{M}$ & $K_{S}$ \\
\hline
\end{tabular}

The outputs of the fuzzy system $i(i=1,2)$ can be expressed as:

$$
\begin{aligned}
\lambda_{i}= & \frac{\sum_{j} \mu_{i j} \lambda_{i j}}{\sum_{k} \mu_{i k}}=\sum_{j} \mu_{i j} \lambda_{i j} \\
K_{i}= & \frac{\sum_{j} \mu_{i j} K_{i j}}{\sum_{k} \mu_{i k}}=\sum_{j} \mu_{i j} K_{i j}
\end{aligned}
$$


The membership functions are expressed as described in table II. Their differentials with respect to $e_{i}$ are expressed in table III.

Based on the new expression of $\lambda$ which depends on the time, the expression of $\dot{s}$ becomes as follows:

$$
\dot{s}=M^{-1}(\tau-C \dot{q}-G)-\ddot{q}_{d}+\lambda \dot{e}+\dot{\lambda} e
$$

with:

$$
\dot{\lambda}_{i}=\sum_{j} \dot{\mu}_{i j} \lambda_{i j}=\sum_{j} \frac{d \mu_{i j}}{d e_{j}} \lambda_{i j} \dot{e}_{j}
$$

The control law is expressed by:

$$
\tau=\tau_{e q}+\Delta \tau
$$

where $\tau_{e q}$ is the equivalent control which is the required control which ensures $\dot{s}=0$. However, the term $\Delta \tau$ is responsible for the robustness of the control law. Then:

$$
\tau_{e q}=C \dot{q}+G+M\left[\ddot{q}_{d}-\lambda \dot{e}+\dot{\lambda} e\right]
$$

and:

$$
\Delta \tau=-M K(e) \operatorname{sign}(s)
$$

Thus, the control law can be expressed as:

$$
\tau=C \dot{q}+G+M\left[\ddot{q}_{d}-\lambda \dot{e}+\dot{\lambda} e-K(e) \operatorname{sign}(s)\right]
$$

Consequently, based on the new expression of $\lambda$ which depends on the time, the derivative of the sliding function $s$ becomes as follows:

$$
\dot{s}=-K(e) \operatorname{sign}(s)
$$

In figures 2 and 3 , evolutions of $\lambda_{i}\left(e_{i}\right)$ and $K_{i}\left(e_{i}\right)$ are presented. Observing these figures, it is clear that $\lambda_{i}\left(e_{i}\right)$ and $K_{i}\left(e_{i}\right)$ are positive functions.

The Lyapunov function associated to the system is:

$$
V_{1}=\frac{1}{2} s^{T} s
$$

Its differential with respect to time gives :

$$
\dot{V}_{1}=-s^{T} K(e) \operatorname{sign}(s)=-\sum_{i} K_{i}\left(e_{i}\right)\left|s_{i}\right|<0
$$

where $K_{i}\left(e_{i}\right)$ is a positive function (see figures 2 and 3 ).

Equation (16) guarantees the fact that the state system converges to the sliding surface $s=0$ and remains on it. Now, we should show that if the state system is on the sliding surface, the error converges to zero. For this reason, let's consider a second Lyapunov function as:

$$
V_{2}=\frac{1}{2} e^{T} e
$$

Its differential with respect to time is expressed as:

$$
\dot{V}_{2}=-e^{T} \lambda(e) e=-\sum_{i} \lambda_{i}\left(e_{i}\right) e_{i}^{2}<0
$$

since $\lambda_{i}\left(e_{i}\right)$ is a positive function (see figures 2 and 3 ).

In figures 2 and 3 , evolutions of sliding surfaces in planes $\left(e_{i}, \dot{e}_{i}\right)$ are presented. In this case, sliding surfaces are not straight lines but curves.

\section{Simulation Results}

In this section, a comparison between sliding mode and fuzzy sliding mode controllers is presented.

TABLE II

EXPRESSIONS OF MEMBERSHIP FUNCTIONS OF FUZZY SYSTEMS $i(i=1,2)$.

\begin{tabular}{||l||c|c|c|c|c|c||}
\hline$e_{i} \in$ & ]$\left.-\infty,-e_{i M}\right]$ & ]$\left.-e_{i M},-e_{i m}\right]$ & ]$\left.-e_{i m}, 0\right]$ & ] $\left.0, e_{i m}\right]$ & ]$\left.e_{i m}, e_{i M}\right]$ & ]$e_{i M},+\infty[$ \\
\hline \hline$\mu_{i 1}$ & 1 & $-\frac{e_{i}+e_{i m}}{e_{i M}-e_{i m}}$ & 0 & 0 & 0 & 0 \\
\hline$\mu_{i 2}$ & 0 & $\frac{e_{i}+e_{i M}}{e_{i M}-e_{i m}}$ & $-\frac{e_{i}}{e_{i m}}$ & 0 & 0 & 0 \\
\hline$\mu_{i 3}$ & 0 & 0 & $\frac{e_{i}+e_{i m}}{e_{i m}}$ & $-\frac{e_{i}-e_{i m}}{e_{i m}}$ & 0 & 0 \\
\hline$\mu_{i 4}$ & 0 & 0 & 0 & $\frac{e_{i}}{e_{i m}}$ & $-\frac{e_{i}-e_{i M}}{e_{i M}-e_{i m}}$ & 0 \\
\hline$\mu_{i 5}$ & 0 & 0 & 0 & 0 & $\frac{e_{i}-e_{i m}}{e_{i M}-e_{i m}}$ & 1 \\
\hline
\end{tabular}

TABLE III

EXPRESSIONS OF THE DERIVATIVES OF MEMBERSHIP FUNCTIONS OF FUZZY SYSTEMS $i(i=1,2)$.

\begin{tabular}{||c||c|c|c|c|c|c||}
\hline$e_{i} \in$ & ]$\left.-\infty,-e_{i M}\right]$ & ]$\left.-e_{i M},-e_{i m}\right]$ & ]$\left.-e_{i m}, 0\right]$ & ] $\left.0, e_{i m}\right]$ & ]$\left.e_{i m}, e_{i M}\right]$ & ]$e_{i M},+\infty[$ \\
\hline \hline$\frac{d \mu_{i 1}}{d e_{i}}$ & 0 & $-\frac{1}{e_{i M}-e_{i m}}$ & 0 & 0 & 0 & 0 \\
\hline$\frac{d \mu_{i 2}}{d e_{i}}$ & 0 & $\frac{1}{e_{i M}-e_{i m}}$ & $-\frac{1}{e_{i m}}$ & 0 & 0 & 0 \\
\hline$\frac{d \mu_{i 3}}{d e_{i}}$ & 0 & 0 & $\frac{1}{e_{i m}}$ & $-\frac{1}{e_{i m}}$ & 0 & 0 \\
\hline$\frac{d \mu_{i 4}}{d e_{i}}$ & 0 & 0 & 0 & $\frac{1}{e_{i m}}$ & $-\frac{1}{e_{i M}-e_{i m}}$ & 0 \\
\hline$\frac{d \mu_{i 5}}{d e_{i}}$ & 0 & 0 & 0 & 0 & $\frac{1}{e_{i M}-e_{i m}}$ & 0 \\
\hline
\end{tabular}



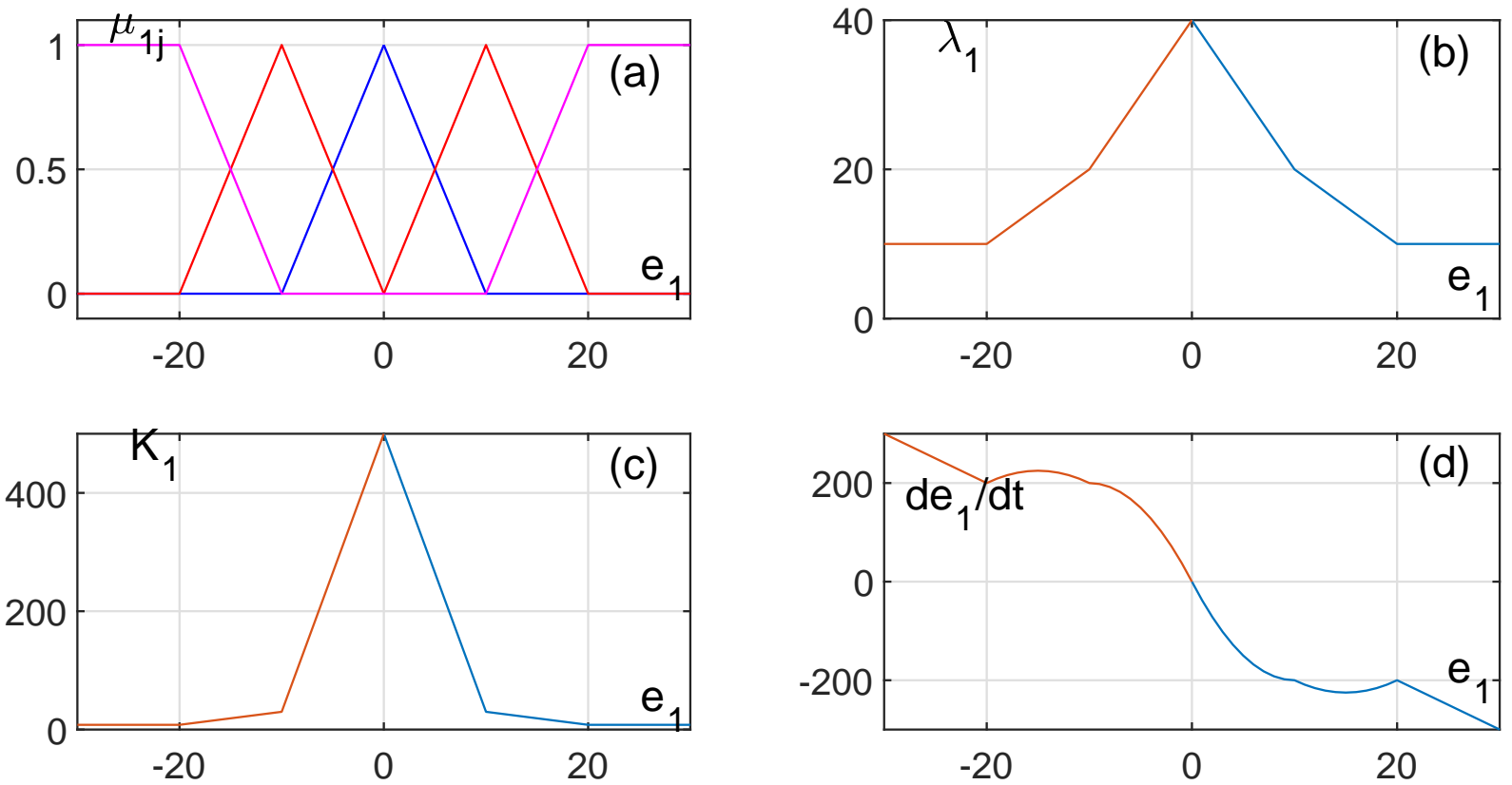

Fig. 2. The evolutions of: (a) membership functions $\mu_{1 j}$, (b) $\lambda_{1}\left(e_{1}\right)$, (c) $K_{1}\left(e_{1}\right)$, and (d) the sliding surface $s_{1}\left(e_{1}, \dot{e}_{1}\right)=0$ in the plane $\left(e_{1}, \dot{e}_{1}\right)$
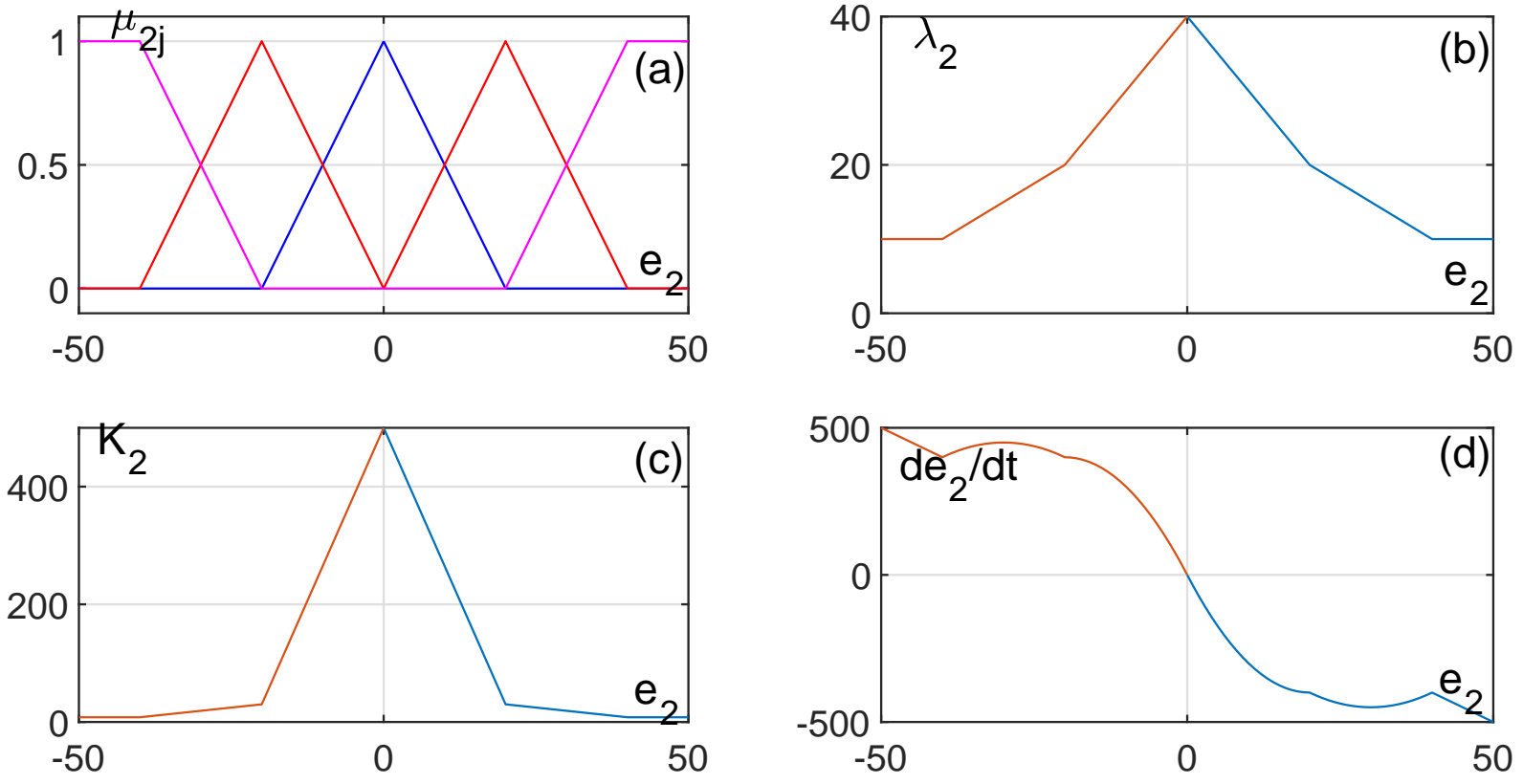

Fig. 3. The evolutions of: (a) membership functions $\mu_{2 j}$, (b) $\lambda_{2}\left(e_{2}\right),\left(\right.$ c) $K_{2}\left(e_{2}\right)$, and (d) the sliding surface $s_{2}\left(e_{2}, \dot{e}_{2}\right)=0$ in the plane $\left(e_{2}, \dot{e}_{2}\right)$ 
Figures 4 and 5 represent the evolution of positions, speeds, applied torques and the evolution of the position errors of hip and knee joints, respectively, using sliding mode controllers. From these figures, it is shown that at the beginning the errors are high which cause the raised values of the torques. For this reason, a fuzzy sliding mode controller is proposed. Figures 6 and 7 show the evolution of positions, speeds, applied torques and position errors using the proposed controller. In order to test the robustness of the proposed controller, we have applied $+50 \%$ variations on masses and $+25 \%$ variations on lengths, representing 13 aged years aged kids.

Figures 8 and 9 represent results given by sliding mode controllers, and figures 10 and 11 represent results given by fuzzy sliding mode controllers. It is obvious that fuzzy sliding mode controllers give better results illustrated by smaller applied torques.
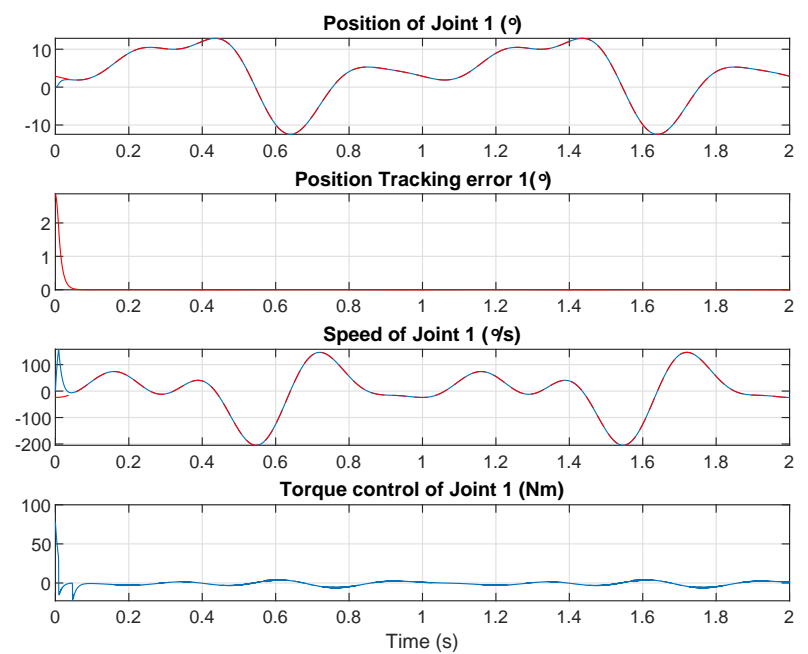

Fig. 4. Sliding mode control of hip joint, dashed line: desired trajectory, continuous line: actual trajectory.
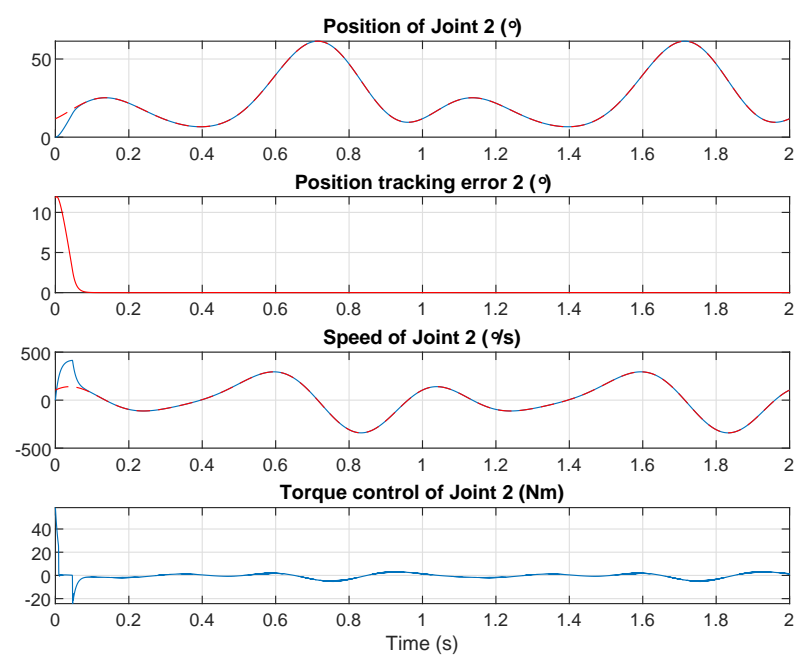

Fig. 5. Sliding mode control of knee joint, dashed line: desired trajectory, continuous line: actual trajectory.
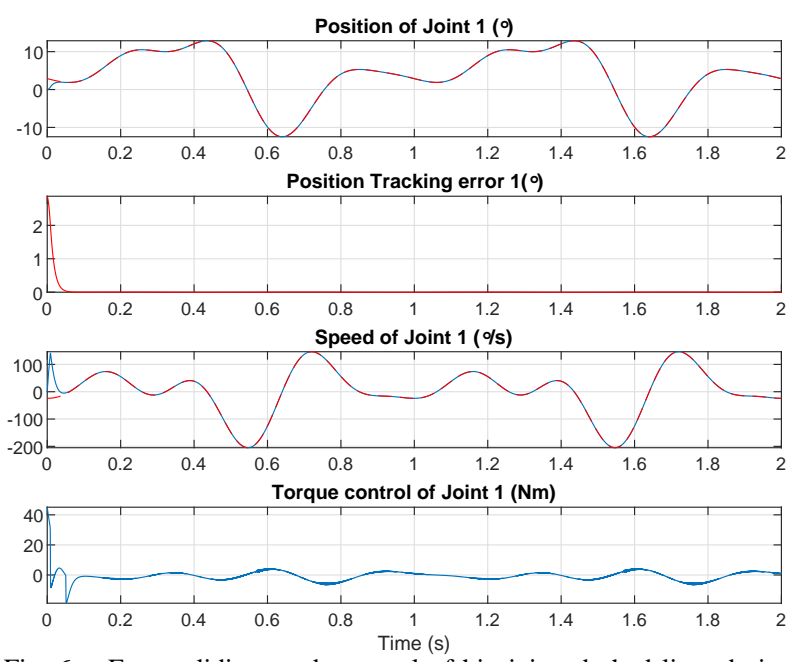

Fig. 6. Fuzzy sliding mode control of hip joint, dashed line: desired trajectory, continuous line: actual trajectory.
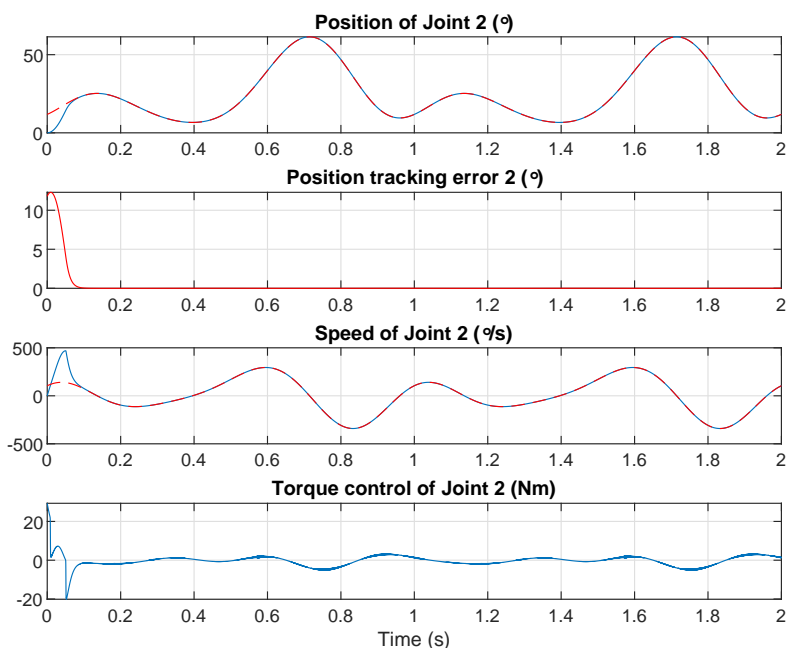

Fig. 7. Fuzzy sliding mode control of knee joint, dashed line: desired trajectory, continuous line: actual trajectory.
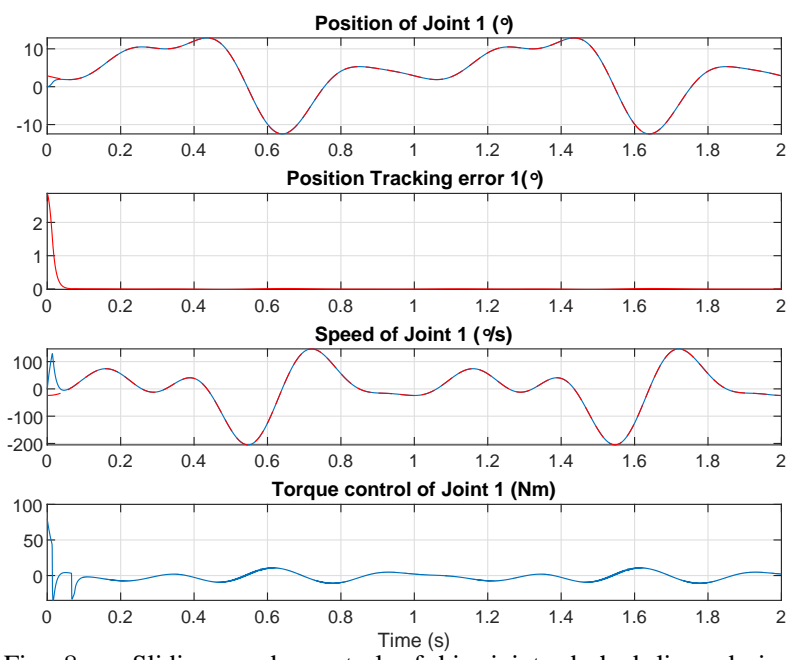

Fig. 8. Sliding mode control of hip joint, dashed line: desired trajectory, continuous line: actual trajectory, with $+50 \%$ variations on masses and $+25 \%$ variations on lengths. 

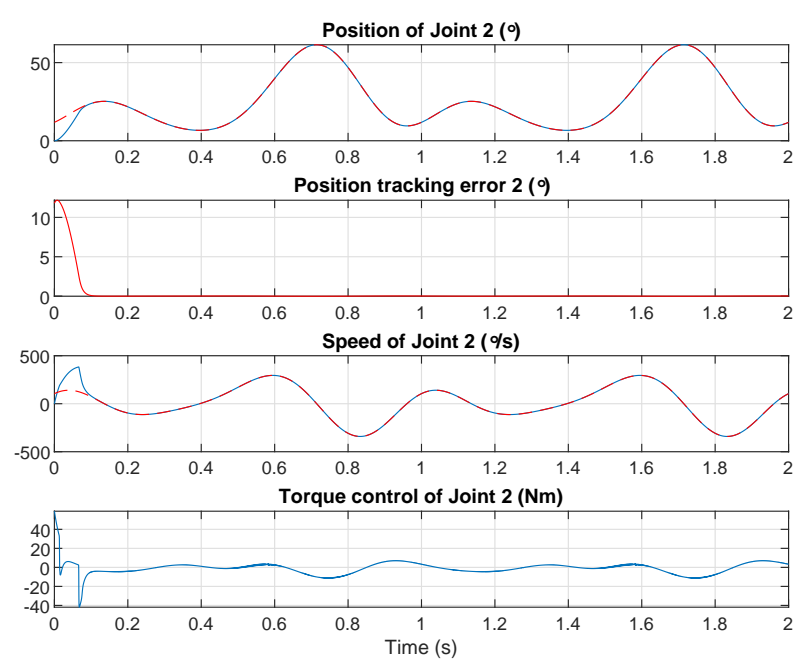

Fig. 9. Sliding mode control of knee joint, dashed line: desired trajectory, continuous line: actual trajectory, with $+50 \%$ variations on masses and $+25 \%$ variations on lengths.
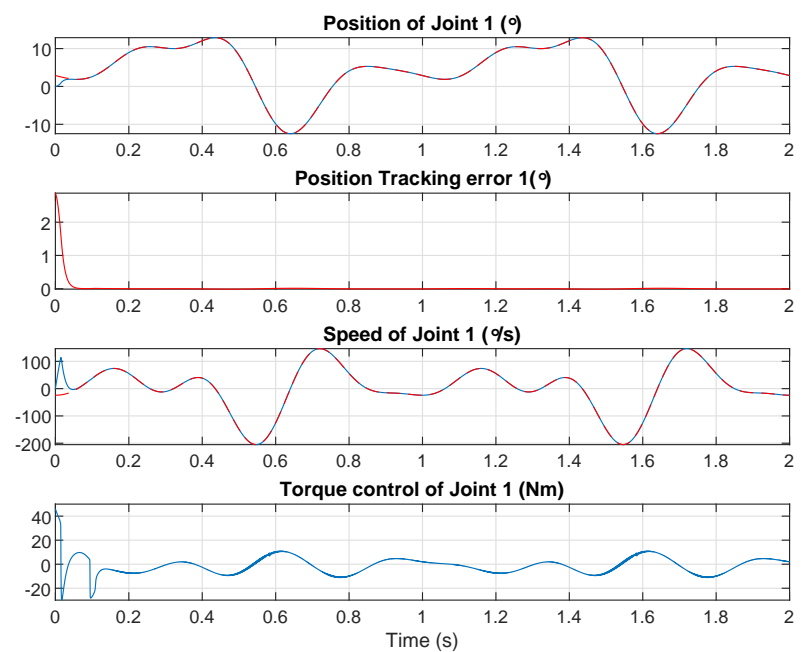

Fig. 10. Fuzzy sliding mode control of hip joint, dashed line: desired trajectory, continuous line: actual trajectory, with $+50 \%$ variations on masses and $+25 \%$ variations on lengths.
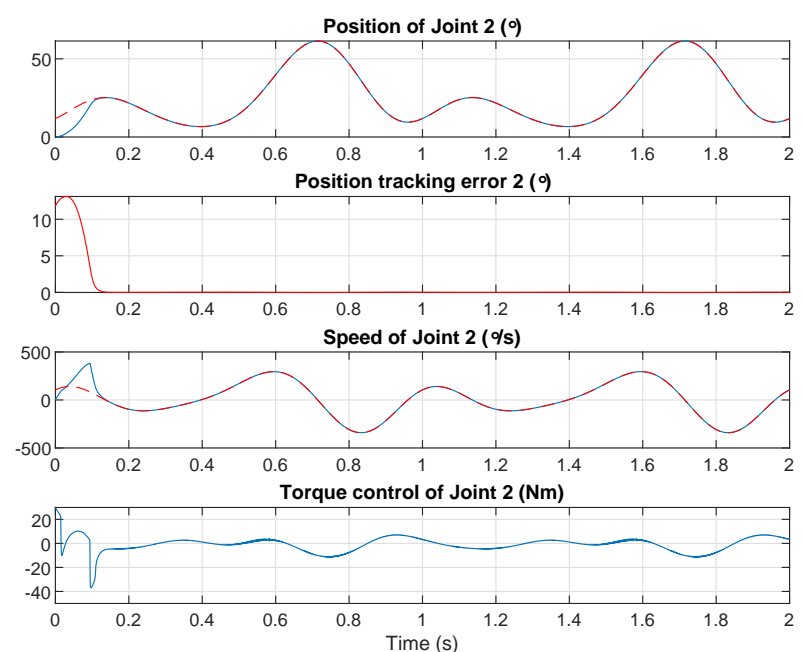

Fig. 11. Fuzzy sliding mode control of knee joint, dashed line: desired trajectory, continuous line: actual trajectory, with $+50 \%$ variations on masses and $+25 \%$ variations on lengths.

\section{CONCLUSION}

This paper concerns the control of lower limb exoskeletons used for the rehabilitation of children suffering from cerebral palsy. In this context, two controllers have been proposed. First, a sliding mode controller has been implemented. It has been found that the system follows the desired trajectories. However, the applied torques are two high and exceed the actuator limitations. For this reason, we have proposed to design fuzzy systems as supervisors, in order to limit the applied torques when the tracking errors are high. especially at the beginning. The stability of the closed loop system has been ensured using the Lyapunov theory. Simulation results show that the proposed controller is effective. Moreover, it has been shown that the fuzzy sliding mode controllers are robust against parametric variations such as masses and lengths of kid's legs.

\section{REFERENCES}

[1] D. J. Reinkensmeyer, V. Dietz. Neurorehabilitation Technology Springer Int. Publishing, 2nd Ed., 2016.

[2] H. Rifaï, S. Mohammed, K. Djouani, Y. Amirat. Toward Lower Limbs Functional Rehabilitation Through a Knee-Joint Exoskeleton IEEE Trans. on control systems technology, 25(2) :712-719, 2017.

[3] W. Huo, S. Mohammed, J. C. Moreno, Y. Amirat. Lower Limb Wearable Robots for Assistance and Rehabilitation: A State of the Art IEEE Systems Journal, 10(3) :1068-1081, 2016.

[4] D. Banks. What Is Brain Plasticity and Why Is It So Important? [online] http://scitechconnect.elsevier.com/what-is-brainplasticity-why-so-important/, 2016.

[5] G. Zeilig, H. Weingarden, A. Obuchov, A. Bloch, M. Gaides, R. Reuveny and I Ben-Dov. Lokomat walking results in increased metabolic markers in individuals with high spinal cord injury Int. Conf. on Virtual Rehabilitation, ICVR, 119-120, 2015.

[6] A. J. McDaid, C. Lakkhananukun, J. Park. Paediatric robotic gait trainer for children with cerebral palsy IEEE Int. Conf. on Rehabilitation Robotics, 780-785, 2015.

[7] Q. Li, W. Zhang, Y. Feng, R. Liu. Design and Research of Lower Limb Walking-assisted Exoskeleton Robot The 4th Int. Conf. on Control and Robotics Engineering, 2019

[8] S. Cuccurullo. Physical Medicine and Rehabilitation Board Review Demos Medical Publishing, 2004.

[9] H. Rifaï, M. S. Ben Abdessalem, A. Chemori, S. Mohammed, Y. Amirat. Augmented L1 Adaptive Control of an Actuated Knee Joint Exoskeleton: From Design to Real-Time Experiments IEEE Int. Conf. on Robotics and Automation, ICRA, :5708-5714, 2016.

[10] B. Maalej, A. Chemori, N. Derbel. Towards an Effective Robotic Device for Gait Rehabilitation of Children With Cerebral Palsy Int. Conf. on signal, control and communication, 2019.

[11] N. Yousfi, P. Melchior, C. Rekik, N. Derbel and A. Oustaloup. Path Tracking Design Based on Davidson-Cole Prefilter Using a Centralized CRONE Controller Applied to Multivariable Systems. Nonlinear Dynamics, 71(4):701-712, 2013.

[12] B. Maalej, R. Jribi, N. Ayadi, F. Abdelhedi, N. Derbel. On A Robotic Application for Rehabilitation Systems dedicated to Kids affected by Cerebral Palsy IEEE Int. Multi-Conf. on Systems, Signals and Devices, 2018.

[13] B. Maalej, A. Chemori, N. Derbel. Kids' Rehabilitation Through an Intelligent Augmented $L_{1}$ Adaptive Control of Robotic Orthoses IEEE Int. Multi-Conf. on Systems, Signals and Devices, 2019.

[14] R. Jribi, B. Maalej, N. Derbel. Robust Adaptive Feedback Linearization Control of Human Exoskeletons IEEE Int. Multi-Conf. on Systems, Signals and Devices, 2019.

[15] S. Perić, D. Antić, V. Nikolić, D. Mitić, M. Milojković, and S. Nikolić. A new approach to the sliding mode control design: anti-lock braking system as a case study Journal of Electrical Engineering, 65(1) :37-43, 2014. 
[16] S. Frikha, M. Djemel and N. Derbel. A New Adaptive NeuroSliding Mode Control for Gantry Crane. Int. Journal of Control, Automation and Systems, 16:559-565, 2018.

[17] J-J. Slotine and S.S.Sastry. Tracking Control of Non-Linear Systems Using Sliding Surfaces with application to Robot Manipulators Int. Journal of Control, 38(2) :465-492, 1983.

[18] S.-B. Choi, D.-W. Park, and S. Jayasuriya. A time-varying sliding surface for fast and robust tracking control of second-order uncertain systems Automatica, 30(5):899-904, 1994.

[19] Q.P. Ha, D.C. Rye and H.F. Durrant-Whyte. Fuzzy moving sliding mode control with application to robotic manipulators Automatica, 35(4), :607-616, 1999.

[20] H. Medhaffar, M. Feki and N. Derbel. Stabilizing periodic orbits of Chua's system using adaptive fuzzy sliding mode controller Int. Journal of Intelligent Computing and Cybernetics, 2019

[21] Q. Wu, X. Wang, B. Chen, H. WU. Design and Fuzzy Sliding Mode Admittance Control of a Soft Wearable Exoskeleton for Elbow Rehabilitation IEEE Access, 2018.

[22] M. Ghezal, M. Guiatni, I. Boussioud and C. S. Renane. Design and Robust Control of a 2 DOFs Lower Limb Exoskeleton. Int. Conf. on Communications and Electrical Engineering, 2018.

[23] Q. Wu, X. Wang, F. Du, Q. Zhu. Fuzzy Sliding Mode Control of an Upper Limb Exoskeleton for Robot-assisted Rehabilitation IEEE Instrumentation and Measurement Society, 2015. 